\title{
GCU
}

Glasgow Caledonian

University

University for the Common Good

\section{An exploration of student learning for sustainability through the WikiRate student engagement project}

Wersun, Alec; Dean, Bonnie Amelia; Mills, Richard; Perkiss, Stephanie; Acosta, Pilar; Anastasiadis, Stephanos; Gibbons, Belinda; Gonzalez-Perez, Maria Alejandra; Heithaus, Theresa; Jun, Hannah; Mesicek, Roman H.; Bayerlein, Leopold

Published in:

International Journal of Management Education

DOI:

10.1016/j.ijme.2019.100313

Publication date:

2019

Document Version

Author accepted manuscript

Link to publication in ResearchOnline

Citation for published version (Harvard):

Wersun, A, Dean, BA, Mills, R, Perkiss, S, Acosta, P, Anastasiadis, S, Gibbons, B, Gonzalez-Perez, MA, Heithaus, T, Jun, H, Mesicek, RH \& Bayerlein, L 2019, 'An exploration of student learning for sustainability through the WikiRate student engagement project', International Journal of Management Education, vol. 17, no. 3. https://doi.org/10.1016/j.ijme.2019.100313

\section{General rights}

Copyright and moral rights for the publications made accessible in the public portal are retained by the authors and/or other copyright owners and it is a condition of accessing publications that users recognise and abide by the legal requirements associated with these rights.

Take down policy

If you believe that this document breaches copyright please view our takedown policy at https://edshare.gcu.ac.uk/id/eprint/5179 for details of how to contact us. 


\title{
Manuscript Details
}

\section{Manuscript number}

Title
IJME_2019_63_R1

An exploration of student learning for sustainability through the WikiRate Student Engagement Project

Student learning for sustainability through the WikiRate Project
Full Length Article

\section{Article type}

\begin{abstract}
This paper uses student perspectives on learning to highlight the potential contribution of the WikiRate platform to develop knowledge, skills, attitudes and sustainability mindsets of future business leaders. WikiRate originates from a project with a mission of "crowdsourcing better companies" throughanalysis of their Environmental, Social, and Governance (ESG) performance. The project identified a need for an open public repository of data tracking companies' ESG performance, on the grounds that while corporate social responsibility reporting is conducted in public, there are barriers to accessing information in a standardised format. WikiRate provides an open repository for data along with tools for analysis, allowing business students to participate in its interpretation. Seeing potential for this pedagogical innovation to help develop the next generation of responsible managers and leaders, educators in business schools in five countries carried out a survey of 1575 student users of WikiRate to explore what they had learned. Analysis of responses from 549 students using a grounded theory approach found that WikiRate extended students' knowledge, skills and attitudes on several dimensions. The findings suggest that use of WikiRate is a valuable addition to a growing number of open source platforms designed to contribute to the development of competences for sustainability.
\end{abstract}

\section{Keywords}

Taxonomy

Corresponding Author

Corresponding Author's Institution

Order of Authors knowledge for sustainability; skills for sustainability; attitudes for sustainability; developing a sustainability mindset; pedagogies for PRME; pedagogical innovation for responsible management education.

Pedagogy, Innovation, Learning, Sustainable Development

Alec Wersun

Glasgow Caledonian University

Alec Wersun, Bonnie Dean, Richard Mills, Stephanie Perkiss, Pilar Acosta, Stephanos Anastasiadis, Belinda Gibbons, Maria Alejandra Gonzalez-Perez, Theresa Heithaus, Hannah Jun, Roman Mesicek

\section{Submission Files Included in this PDF}

\section{File Name [File Type]}

Response to Reviewers_IJME 2019_63ResubmissionAW170619.docx [Response to Reviewers (without Author Details)]

Highlights pageResubmission170619.docx [Highlights]

IJME2019TitlePageResubmission170619.docx [Title Page (with Author Details)]

IJMEManuscriptFinalWithoutAuthorldentifierResubmission1706191300.docx [Manuscript (without Author Details)]

IJMEFigure1AWResubmission170619.docx [Figure]

Table 1 Partners, modules, student numbersResubmission170619.docx [Table]

IJMETable 2Resubmission170619.docx [Table]

To view all the submission files, including those not included in the PDF, click on the manuscript title on your EVISE Homepage, then click 'Download zip file'. 
Title: An exploration of student learning for sustainability through the WikiRate Student Engagement Project

\section{Highlights:}

1. The WikiRate student engagement project is an open source pedagogical innovation that develops knowledge, skills and attitudes (KSA) for sustainability along several dimensions.

2. The WikiRate pedagogical innovation is helpful in developing a sustainability mindset.

3. Responsible management educators can make greater use of the student's voice to understand what students learn from different pedagogies. 
Paper Title: An exploration of student learning for sustainability through the WikiRate Student Engagement Project

\section{Authors:}

Alec Wersun*

Glasgow School for Business and Society

Glasgow Caledonian University

Glasgow G4 0BA

Scotland, United Kingdom

E: a.wersun@gcu.ac.uk

* Corresponding author

2. Bonnie Amelia Dean, University of Wollongong, Australia.

Email: bonnie_dean@uow.edu.au

3. Richard Mills, University of Cambridge, UK.

Email: richard@wikirate.org

4. Stephanie Perkiss, University of Wollongong, Australia.

Email:

5. Pilar Acosta, Universidad ICESI, Colombia.

Email: mdacosta@icesi.edu.co

6. Stephanos Anastasiadis, Royal Holloway, University of London, UK.

Email: Stephanos.Anastasiadis@rhul.ac.uk

7. Belinda Gibbons, University of Wollongong, Australia.

Email: bgibbons@uow.edu.au

8. Maria Alejandra Gonzalez-Perez, Universidad EAFIT, Colombia.

Email: mgonza40@eafit.edu.co

9. Theresa Heithaus, WikiRate Organisation, Germany.

Email: theresa@wikirate.org

10. Hannah Jun, Ewha Womans University, South Korea.

Email: hannahjun@ewha.ac.kr

11. Roman H. Mesicek, IMC University of Applied Science Krems, Austria.

Email: Roman.Mesicek@fh-krems.ac.at 


\section{Introduction}

The launch of the UN Global Compact's Principles for Responsible Management Education $\left(\mathrm{PRME}^{1}\right)$ in 2007 can be seen as a widespread acknowledgement that students of business and management need a form of education that enables them to make a positive contribution to both business and society. PRME's aim of realising the United Nations' Sustainable Development Goals (SDGs) through responsible management education is built on six guiding Principles, designed to encourage business schools and universities to recognise their role as change agents and champions of sustainable development. Consequently over 700 signatories to PRME have committed to adapt their institutional strategies, curricula, research agendas, and external engagement activities to "develop the capabilities of students to be future generators of sustainable value for business and society at large and to work for an inclusive and sustainable global economy" (PRME, Principle $1^{2}$ ).

In 2018, the Organisation for Economic Co-operation and Development (OECD), a supporter of the UN's 2030 Agenda for Sustainable Development, published a report on The Future of Education and Skills 2030. In this report the OECD asks: What knowledge, skills, attitudes and values will today's students need to thrive and shape their world? The report emphasises a need for learner agency, the ability to navigate through a complex world as a global citizen through an innate sense of responsibility, and "implies more than just the acquisition of knowledge and skills; it involves the mobilisation of knowledge, skills, attitudes and values to meet complex demands" (OECD, 2018, p.5).

Such questions have encouraged a wave of curricular and pedagogical innovation, examples of which can be found in a special issue of this journal (Parkes, Buono \& Howaidy, 2017) in two editions of the PRME Inspirational Guide (Albareda, Alcaraz, Csuri, Escudero, \& Weybrecht, 2012; Murray, Baden, Cashian, Wersun, \& Haynes, 2014), and in books related to education for responsible management education (e.g. Sunley \& Leigh, 2016; Mothan-Hill, 2017). In this paper we add a more recent innovation being adopted around the world that speaks to PRME Principle $3^{3}$ and “...educational frameworks, materials, processes and environments that enable effective learning experiences for responsible leadership". The innovation is called the 'WikiRate ${ }^{4}$ student engagement project', a public collaborative research platform that gives students the opportunity to critically examine ways in which

\footnotetext{
${ }^{1}$ https//unprme.org

2 http://www.unprme.org/about-prme/the-six-principles.php

${ }^{3}$ http://www.unprme.org/about-prme/the-six-principles.php

${ }^{4}$ https://WikiRate.org
} 
businesses report on their corporate social responsibility activity, and contributions to the Sustainable Development Goals. Educators in five countries analysed feedback about the WikiRate experience from 1575 students to explore the degree to which WikiRate contributes to the development a 'sustainability mindset' in students (Rimanoczy, 2016), through the acquisition and development of new knowledge, skills and attitudes.

\section{Knowledge, skills and attitudes for sustainable development}

A 2010 survey of members of the United Nations Global Compact indicated that sustainability had already become 'truly top of mind for CEOs round the world', a marked change compared with 2007 when sustainability was only just emerging on the periphery of business issues. The report concluded that:

“...CEOs see a critical need for business schools and education systems to focus on developing the next generation of managers and business leaders with the knowledge, skills, attitudes and behaviours to manage sustainability issues as an integral way they think about business" (Lacy, Cooper, Hayward, \& Neuberger, 2010, p.49)

This perspective suggests that education for sustainable development (ESD) and PRME are closely related to professional employment as we seek to develop graduates who will take ESD-related knowledge, skills and attitudes (KSA) in to their workplaces to build a sustainable future. The use of the KSA framework in education and practice derives from Bloom's taxonomy of learning (Krathwohl, Bloom \& Masia,1964). Bloom's model was designed to promote higher forms of thinking in education such as analysing and evaluating, by placing these forms at the pinnacle of an hierarchy, compared to rote learning forms such as understanding and remembering. The taxonomy relates to three domains of learning - the cognitive (mental skills to acquire and retain knowledge), psychomotor (for the development of skills), and the affective (to develop feelings and emotions that can shift attitude and conception of 'self'). The KSA framework is used to design educational activities to shape what participants will know, be able to do (skills), and 'be' (attitude) as a result of a given programme of learning, thereby engaging the head, hands and heart (Sipos, Battisti \& Grimm, 2008). According to Baartman, Bastiaens, Kirschner, and Van der Vleuten (2007) knowledge, skills and attitudes (KSA), when integrated, form the basis of the concept of 'competence', which in the context of sustainability has been defined as "complexes of knowledge, skills and attitudes that enable successful task performance and problem-solving with respect to real-world sustainability problems, challenges and opportunities" (Wiek \& Redman, 2011, p.204). Adopting a competence-based approach to responsible management education and 
sustainability challenges us to rethink traditional educational approaches, and ask what types of knowledge, skills and attitudes (competences) are required and how they can be taught or learned. Laasch \& Moosmayer (2015) argue that responsible management implies that being a competent manager or leader requires competences distinct from those traditionally recognized.

\section{Pedagogical approaches to develop a sustainability mindset}

Extending the KSA framework, recent attention has been drawn to the importance of students developing a sustainability mindset. A sustainability mindset describes the process by which students examine their personal values and ways of thinking and being through opportunities for introspection. In doing so, "the mindset can be seen as a platform, a world-view that creates an interpretative frame for any kind of sustainability initiatives, since it shapes a new way of looking at the world, making meaning of data, analysing problems and exploring possible solutions" (Rimanoczy, 2016, p.164).

The notion of a sustainability mindset offers a useful frame for thinking about designing initiatives in ESD. Rimanoczy (2016, p.168) proposes an instructional framework that educators can use when designing modules or programmes that contribute to a sustainability mindset. The framework suggests that educational activities should be designed in a way that extend knowledge, skills and attitudes through the development of a) Ecoliteracy, through exposure to information about the current state of the world, with an understanding of the impact of our life and actions on the planet; b) Systems intelligence, by highlighting the longterm impacts and interconnectedness of decisions and multi-stakeholder perspectives (Nguyen, Graham, Ross, Maani, \& Bosch, 2012); c) Emotional intelligence (see Chopra \& Kanji, 2010) by helping students to pay more attention to their feelings and the role they play in their everyday life; and d) Spiritual intelligence, which provokes personal reflections on topics such as purpose, sense of calling or life mission.

Fairfield (2018) argues that cultivating a sustainability mindset is a demanding mission that requires students to acquire a basic knowledge and understanding of topics such as ecoliteracy, climate change, other threats to the world, and of approaches that companies are adopting to tackle them. Educators are likely to use traditional educational methods, such as lectures, videos and readings, to convey such knowledge. Given that the development of 
responsible management competences and a sustainability mindset require not only new knowledge, but the development of 'doing' (skills), and 'being' (attitude), Fairfield (2018) suggests that 'hands-on' approaches are more effective for this purpose.

The work of Rimanoczy, Laasch, Moosmayer, Fairfield and others therefore suggests that the ' $h o w$ ' of teaching for sustainability is just as, if not more, important that the 'what', and that active and reflective pedagogies designed to promote self-awareness are best suited for responsible management education. This supports conclusions of Albareda et al. (2012) who foresaw a movement towards a "new frontier" of experiential learning to revolutionise management school learning environments. Active and experiential approaches to business education have increased in recent years as students articulate their preference for high levels of engagement through activity in the classroom (Bell, 2015). This is consistent with a recent review of the literature, which identified problem-based and experiential learning as preferred strategies for teaching sustainability in business schools (Ortiz \& Huber-Heim, 2017).

For example, Ortiz and Huber-Heim (2017) describe an active learning approach to implement a five-step model for learning for sustainability (inform, consult, involve, collaborate and empower). The approach is designed to develop 'cognitive engagement' by involving students in problem formulation, doing some research on a specific topic, problem solving, and critical reflection (Figuero \& Raffluet, 2015). Annan-Diab and Molinari (2017) employ a range of learning strategies including role play and dialogue around real case studies, to advance interdisciplinary education for sustainable development amongst postgraduate MBA students across several countries. Kopnina (2017) describes how students developed critical, innovative and imaginative thinking towards sustainable development and the SDGs through classroom interventions such as critical discussion and project group investigations of corporate cases.

The above examples of active and experiential pedagogies for RME and the SDGs are but a few of the many presented in both academic journals, and more recently in books on the subject (see Sunley \& Leigh, 2016; Molthan-Hill, 2017). Most of the examples in these articles and texts are institution-specific and categorised as examples of 'action learning' 'case study' 'service learning' or similar (see Forray, Leigh \& Goodnight, 2016 for an overview of categories). However, there is a small number of recent pedagogical initiatives that stands out by virtue of them going 'global' and attracting worldwide attention and adoption. Storey, Killian and O'Regan (2017) list amongst these three global teaching and 
learning initiatives, and two student-led initiatives. In the former group are the Sulitest (sustainability literacy test ${ }^{5}$ ), the Aim2Flourish initiative ${ }^{6}$, and Mary Gentille's 'Giving Voice to Values $(\mathrm{GVV})^{7}$; , and in the latter are Enactus ${ }^{8}$ and Oikos $^{9}$. These pedagogical approaches have two defining features. The first lies in the aim of sharing innovative practice globally through the provision of open source materials and resources. For example, the Sulitest has been used in over 850 universities and companies in 67 countries; Aim2Flourish has members from 226 business schools in 74 countries; and GVV has been used in over 1055 business schools, companies and other organisations around the world. Enactus is the world's largest student-driven experiential learning platform that has been used in on 1736 campuses in 36 countries; while Oikos has 45 national chapters around the world. The second defining feature of these approaches is that they can be adapted to fit within different local and global contexts, testimony to which are the numbers of educators and students engaging with the platforms.

While the Sulitest, Aim2Flourish and GVV have been the subject of recent papers in journals with an RME focus (e.g. Parkes et al, 2017) and books (Sunley \& Leigh, 2017), a more recent pedagogical innovation attracting global engagement, called WikiRate, has hitherto attracted less attention and will be the focus of the rest of this paper. This is surprising given that since inception, the project has engaged over 2,000 student researchers at 17 Universities in 11 countries across 32 classes, generating more than 60,000 open data points on corporate sustainability and disclosure. The remainder of this paper will therefore focus on WikiRate and explore the knowledge, skills and attitudes that it helps to extend and foster.

\section{Origins of WikiRate}

WikiRate originates from an EU funded Collective Awareness Platform for Sustainability and Social Innovation (CAPS) project launched in 2013 with a mission of "crowdsourcing better companies" through analysis of their Environmental Social and Governance (ESG) performance (Mills et al., 2016). Research to inform the design of the platform involved surveying the current corporate ESG landscape, and identifying ways in which an open approach and peer production ethos could be mobilised effectively to improve transparency in ESG reporting. The project identified an urgent need for an open public repository of data

\footnotetext{
${ }^{5}$ https://www.sulitest.org/en/index.html

${ }^{6}$ https://aim2flourish.com

7 https://www.darden.virginia.edu/ibis/initiatives/giving-voice-to-values/

${ }^{8}$ http://enactus.org

${ }^{9}$ https://oikos-international.org
} 
tracking companies' ESG performance, on the grounds that while Corporate Social Responsibility reporting is conducted in public, but there are barriers to accessing the information in a standardised format that lends itself to analysis. Analyses of, and ratings built upon, such data can exert power over companies' behaviour in certain circumstances (Sharkey \& Bromley, 2015), but the public at large (including universities) have no access to the data or the most influential ratings that use it (e.g. $\mathrm{KLD}^{10}$ ratings). WikiRate aims to build an open repository for this data along with tools for analysis, to increase public demand for the data, allowing a broader range of stakeholders to participate in its interpretation, and in turn drive companies to behave in a more ethical manner.

\section{Relevance of WikiRate to responsible management education (RME)}

Companies are increasingly expected to, and in some cases legally required to, report on their Environmental, Social and Governance (ESG) performance, and contributions to sustainable development and the SDGs. This may explain why one of the most widely used concepts by educators of responsible management and sustainability is the "the triple bottom line" (TBL), first coined in 1994 by John Elkington, the founder of a British consultancy called SustainAbility (Elkington, 2018). Elkington's argument was that companies should move beyond the traditional measure of corporate profit - the so-called "single bottom line" of the profit and loss account - and include measures (in some shape or form) of how socially responsible an organisation has been in the way it operates, as well as how environmentally responsible it has been. More importantly, Elkington (2018) claims that the stated goal of the TBL from the outset was system change and the transformation of capitalism, something that is far from being realised. The triple bottom line (TBL) thus consists of 'three Ps': profit, people and planet, and aims to measure the financial, social and environmental performance of the corporation over a period of time.

The TBL concept reflects moves in recent decades to develop more integrated approaches to corporate social responsibility and reporting, as evidenced by the establishment of reporting standards, and the adoption of these standards by many large corporations, and particularly members of the United Nations Global Compact (UNGC). The Global Reporting Initiative's (GRI) G3, and more recently G4 standards have the greatest levels of adoption by companies

$10 \mathrm{https}: / /$ bit.ly/2LlJLut 
(Mills et al, 2016), and measures a company's ESG performance. The G4 defines 91 indicators for measuring sustainability impacts and guidelines state that companies should report on all of the 91 sustainability indicators that they deem "material" (relevant) to their business.

The degree to which companies report by using indicators varies between industries and companies, but the voluntary production of Corporate Social Responsibility (CSR) reports is now commonplace among large companies due to increased stakeholder demand (Aguinis \& Glavas, 2012), as well as demand from consumers (Christmann \& Taylor, 2006).

Additionally, recent legislation requires:

- companies that trade in the UK to publish statements about the steps they take to avoid slavery in their supply chains ${ }^{11}$.

- companies based in the EU with more than 500 employees to report on ESG performance ${ }^{12}$.

- companies that trade in the United States and file with the Security and Exchange Commission (SEC) to produce "Conflict Minerals Reports ${ }^{13}$ ".

- Indian companies over a certain size to spend $2 \%$ of their profits on CSR activities $^{14}$.

The majority of CSR reports are delivered as PDF documents (and/or online "Integrated Reports") following a structure determined by the reporting company. The company has full control over this document, and freedom to present itself in the best possible light. One of the benefits companies seek when they engage in voluntary CSR reporting is an improvement in their reputation (Brammer \& Pavelin, 2006). However, some CSR reports are written in a way that maximises this gain, and in some cases present disinformation or "greenwashing" (Mahoney, Thorne, Cecil \& LaGore, 2013). To analyse a company's ESG performance based on their reporting, one must first interrogate that reporting and extract concrete information, then contextualize it by, for example, comparing to other companies of a similar size and/or operating in the same industry. However, this is a challenge as it involves picking comparable pieces of information out of the reporting output of every company being

\footnotetext{
${ }^{11} \mathrm{https}$ //www.gov.uk/government/collections/independent-review-of-the-modern-slavery-act

12 https://ec.europa.eu/anti-trafficking/eu-policy/guidelines-non-financial-reporting_en

${ }^{13} \mathrm{https://www.sec.gov/news/statement/reconsideration-of-conflict-minerals-rule-implementation.html}$

${ }_{14}$ http://www.mca.gov.in/SearchableActs/Section135.htm
} 
assessed. WikiRate makes this job easier as it offers a public repository where this data can be stored, and provides users with a set of tools for analysis and critique. Stakeholder demand is often cited as a driver of improved CSR reporting (Aguinis \& Glavas, 2012), and WikiRate aims to demonstrate and increase the demand for this data by making it available in a usable format.

As WikiRate works on wiki principles, in terms of a peer production effort, it offers business and management students the opportunity to engage as equals in the discourse about what we really want from CSR and the reporting thereof.

\section{WikiRate as a pedagogical tool: how does it work?}

In general terms, WikiRate provides a platform for educators and their students to:

a) collect and store available sources of information (e.g. corporate sustainability reports) about companies ESG performance in one public place;

b) extract tightly defined quantitative data from these sources, or make categorical assessments, following well defined methodologies, based on these sources;

c) identify gaps or weaknesses with the data that companies are providing about their social and environmental performance;

d) use the data to assess performance, thinking critically about its utility and how it could be improved; and

e) lobby for greater disclosure of that information.

The Wikirate platform is managed by a team in Berlin that works with university professors and partner organisations to set up an online project that aligns with the learning objectives or research interests of the educator. Before setting up the project, educators decide which companies and quantitative measures (metrics), and/or aspects of corporate reporting they would like to include in the research. For example, the focus may be on corporate members of the United Nations Global Compact in specific countries or regions of the world (e.g. Europe, North or South America, Asia) and companies in specific sectors (e.g. energy, chemicals, mining, fashion, consumer goods). Aspects of corporate reporting that are researched include GRI metrics (e.g. greenhouse gas emissions, water use, gender equality, anti-corruption), and one or more of the United Nations sustainable development goals (SDGs). The focus of research done inside Wikirate is on large companies for two main 
reasons. The first is that large companies are more likely to have commensurate impacts (positive and negative) on society due to their size and geographic scope and there is growing pressure on these companies to report the nature of these impacts. The second is that large companies are more likely than small ones to produce publicly available data, in the form of annual reports and sustainability reports. The flexibility of the online platform to determine the scope of research and analysis carried out by students means that it can be easily adapted to the needs of different classrooms and sustainability foci. A recent publication by Perkiss et al. (2018) presents a summary of seven case studies of Wikirate use from different parts of the world, and in different disciplines.

Once the scope of the research is agreed, the Wikirate team helps with the set up of project pages with a customised project name, a description of the project scope and aims, and one or more topic area tags that relate to the project. The educator chooses a selection of years that students are to research, and with the Wikirate team, make available to students links (url) to the list to the websites of companies in the project, as well as a list (with definitions and explanations) of metrics. A metric is used to ask the same question of multiple companies, and it allows the answers to be stored on the basis of one answer per company per year. Each metric answer must cite a public source of evidence (e.g. 2018 sustainability report, p.42), and each answer can be discussed on the WikiRate platform to add details like how/where the answer was derived from the source. Metrics specify which kind of data are required (usually numerical or categorical, with a set of options being defined for categorical metrics). Crucially, any metric can be answered "Unknown", which is a way of recording that a user sought the answer but could not find it - making WikiRate well suited to mapping out company disclosures and identifying where the gaps are.

The educator then allocates each student (or team of students) to a company. Projects autogenerate "research pages", when a user clicks the Research button on a company they are taken to a research page, which shows one of the metric questions and a space to add the answer (or the existing answer if one exists) on the left side of the screen, and a space for browsing and viewing relevant sources on the right side of the screen as in Figure 1 below.

Figure 1 here: Example of Wikirate Project Research Page 
As the researcher adds answers to the metric questions they are rewarded with badges and move on to the next question or year to add more data on the same page.

To promote data quality, WikiRate offers two checking tools. A "checked it" button allows a user to confirm that they have checked a data-point and found it to be accurate (if they find it to be inaccurate, they edit it, in wiki style, with a full version history being available for every data-point). A "please check this" button allows a user to add a data-point they are not sure about, flagging it for review by other users. Most of the PRME cohorts that have run WikiRate projects integrate peer review, where each student is asked to check the answers produced by one of their peers, in addition to conducting their own research.

WikiRate has been designed around metrics for a number of reasons. First of all it allows for the challenging task of understanding corporate impacts to be broken down into small chunks. Secondly, standard questions that are asked of every relevant company is a fair way to assess sustainability, as compared to focusing on reports that follow bespoke structures or investigations that focus on one company and ignore its competitors. Thirdly, quantitative metric data is amenable to analysis and the production of ratings. Now, as the volume of open data on the platform has grown to over 460,000 data-points, there is enough available data that some users may start with analysis directly and only perform data collection to the extent that the data they require is not yet on the platform.

Seeing the potential for this pedagogical innovation to contribute to the development of the next generation of responsible managers and leaders, WikiRate and signatories to the Principles for Responsible Management Education (PRME), launched a pilot project in 2016. By engaging students with real-world practice of CSR and sustainability reporting using the WikiRate platform, it is hoped that business and management students will deepen and broaden their knowledge of sustainability and why it is important, develop a range of analytical skills by reviewing corporate sustainability reports, and by developing such knowledge and skills, shape their sustainability mindset.

\section{Exploring learning with WikiRate through an international research collaboration}

The WikiRate and PRME pilot project prompted seven users of WikiRate, in business schools in five countries, to develop a collaborative research project aimed at exploring student learning with WikiRate. Table 1 provides details of project partners, modules in to which 
WikiRate was embedded at undergraduate or postgraduate levels, and a breakdown of the 1575 student users. The research took place in the first half of 2018. While the assignments within each module differed according to the module content or topic, number of students enrolled and year-level of students, all students participated in the WikiRate platform in a similar way. That is, in all cases students were required to independently or in groups research organisations, upload a recent company sustainability report inside the WikiRate platform, input record and analyse evidence (metrics) of corporate self-reporting in relation to the United Nations sustainable development goals.

\section{TABLE 1 HERE}

The general approach taken in this article, shaped by the Call for Papers for this Special Issue to capture student voices, was to assess the use of the WikiRate innovation from a student, as opposed to an educator's perspective. According to Warwick, Wyness \& Conway (2017) there is a relative gap in pedagogical research into sustainability education innovations in business schools from a student perspective, and this paper seeks to make a contribution in this area. An educator's perspective on the use of WikiRate can be found in other work by the authors (see Perkiss et al., 2018; Perkiss et al. 2020).

\section{Data Collection}

The researchers adopted a collaborative and participatory approach to design the research. Online video conferencing technology (Zoom) was used to enable participants in different countries and time zones to 'meet', discuss and agree data collection and analysis methods. Email was used to follow up on decisions made during the online meetings. This approach fostered a strong empowerment ethic, which is congruent with the ESD paradigm (Sterling, Warwick \& Wyness, 2016).

Given the participation of educators and students in five countries, researchers opted for an online survey, with open and closed questions, and ended up using Qualtrics ${ }^{15}$. The survey language was English, as it is widely used in educational provision in all participant institutions, and students in all countries were judged to be sufficiently proficient in English to complete survey questions. Data was obtained through a single survey instrument, administered at the end of engagement with WikiRate, via a link to the survey made available by either an email to the student, or posted on the module's online learning platform. The

\footnotetext{
${ }^{15} \mathrm{https://www.qualtrics.com/uk/}$
} 
researchers paid careful attention to ethical considerations, which were covered by a global Human Research Ethics approval. From an enrolment of 1,575 students globally we received 549 student responses to one or all of the seventeen survey questions, with representative participation from all institutions, giving an overall 35\% response rate. While the closed questions focused mainly on capturing student demographics, the amount of time spent using WikiRate, and location data, the open questions covered a range of topics including the technical use of WikiRate, assessment experiences, and the potential use and recommendations for WikiRate. The focus of this paper was to analyse two of the open-ended questions to explore the extent to which WikiRate fosters the development knowledge, skills and attitudes that build towards a sustainability mindset. The specific survey questions analysed in this case were:

1. How have your thoughts/attitudes on the sustainable development goals (SDGs), sustainability, and corporate social responsibility (CSR) been impacted or changed since engaging in this activity?

2. How do you think this will affect you as a practitioner as you move into your professional practice?

For question 1, 488 students responded (31\%) and for question 2, the number of responses was $475(30.2 \%)$.

\section{Data Analysis}

The researchers used the competence-based framework of knowledge, skills and attitudes (KSA) as an overarching framework for analysis for two main reasons. Firstly, as the KSA domains have been presented as useful in addressing sustainability in educational contexts (e.g. Hesselbarth \& Schaltegger, 2013, Lozano et al., 2011; Stubbs \& Schapper, 2011; WEC and Net Impact, 2011). Secondly, as according to Laasch and Moosmayer (2015:15), “...the KSA - knowledge, skills, attitudes - framework seems among the more dominant and prominent ones and has also shown the widest applicability".

Analysis was carried out in two main phases. First of all two researchers independently went through the student responses and colour coded these in to three themes, according to whether the comment was more related to knowledge, skills or attitude. In some cases, different sections of individual responses carried different coding as parts of a comment were judged to be about knowledge, and another about skills or attitude. In the second phase, the researchers used a grounded theory approach (Glaser \& Strauss, 1967) whereby an attempt was made to 
develop sub-themes within the three domains of knowledge, skills and attitudes, to illuminate the data. To test the relevance of the sub-themes, the researchers attempted to 'saturate' the categories with as many appropriate quotations as possible. Once this was done by each of the researchers, results were compared and agreement reached on final sub-themes against which to report findings. These can be found in Table 2 below.

TABLE 2 HERE

\section{Findings and Discussion}

Analysis of data revealed 15 sub-themes relating to the overarching themes of knowledge, skills and attitudes. In the sections below, each sub-theme is illustrated through examples, centralising student voices to illustrate each major theme. Following the presentation of findings, discussion ensues reflecting on the role of the WikiRate Student Engagement project for cultivating students' sustainability mindsets.

\section{Knowledge}

Analysis of data revealed five sub-themes centred on knowledge development. The first subtheme exposed an extension of knowledge in relation to the concepts of CSR and the SDGs. Students articulated a new consciousness upon learning these for the first time. Statements from students reflected a movement from unawareness to understanding of terms, for example "I have just learned what they actually mean" $\left(270^{16}\right)$ and "I have a better understanding of what the goals mean, having seen them printed all over the place but never really knowing what they meant until now" (42). This finding reflects an awareness of dispositional knowledge, as students are able to name and make sense of these terms.

The second knowledge sub-theme also relates to an understanding of CSR, however embeds this knowledge in the context of organisational sustainability practices. Students discuss their expanded knowledge of how organisations may act sustainability, "I did not know how companies act "sustainable" and which different forms are possible. It was very interesting to me, to get informed how sustainable business management works" (385). This knowledge was reflected as practical understanding of what sustainability looks like but also how the SDGs may work for real companies, represented through statements such as "[previously] I thought it was far from our life and theoretical" (9), "It has opened my eyes to real world situations" (98), and "[it has helped] me to see business activities in a more broader sense".

\footnotetext{
${ }^{16}$ Bracketed numbers after quotations indicate the number assigned to a student who responded to the survey
} 
This theme is also captured by comments around an increased understanding of why these goals are important and how that is related to organisational values:

"I was somewhat dismissive of some issues, such as the different forms of environmental output, prior to conducting this research. My position on these issues has been significantly expanded through an awareness of the substantial nature of these outputs and the failure of the companies to address these issues in any meaningful way." (244)

"Prior to undertaking the module, I have completed two other modules that raised my awareness of CSR, however by researching the issues in-depth, I noticed a change in my way of thinking about certain social and environmental aspects". (471)

These comments signal student learning of organisational sustainability through the WikiRate activity, in a way that reflects an understanding of the value of CSR practices.

The third knowledge sub-theme that emerged was enlightenment around disclosure practices. Given the hands-on nature of the activity, this sub-theme suggests the utility of WikiRate as an experiential learning activity. Students commented on how companies disclose information but also expressed surprise around the degree to which information is not reported. Statements included "[it] made me realise how many companies do and don't disclose this information" (337) and "my thoughts on sustainable development goals, sustainability and corporate social responsibility have been impacted since engaging in this activity as it made me more aware of the lack of disclosure exhibited by a lot of companies regardless of whether or not their public reputation was positive or not" (353).

Analysis of data revealed a fourth sub-theme connecting this new knowledge of organisational sustainability to the student's own future professional practices and ambitions. In some cases this knowledge is placed in contrast with other pedagogical strategies, for example "[this activity] has given me a deeper understanding of these concepts as well as an idea of how they could be used within my life or a job instead of just knowing them for an exam" (266). It was also seen in students commenting on how they will use these insights to inform for whom and where they will work, "[this experience] made me realise how I want to work for a firm who is a strong believer in these SDGs" (365) and "I will now have something else to look at when applying for jobs" (147).

The fifth and final knowledge sub-theme was an awareness of WikiRate. For some students this was a practical awareness of WikiRate as a new tool for CSR reporting, for example, "Through WikiRate I am able to understand the involvement of businesses in SDG's and CSR 
and have a higher knowledge of how important it is and how it can be measured" (113) and "WikiRate provided a good way to bring the theories to life and helped me to learn them better as I could compare them to and research them through real life examples and stimuli" (319). While for other students, the value of WikiRate as an enabler of social good emerges. One student proclaims that "WikiRate allowed us to make a small contribution to something big and important which is great" (69). Another student expresses implications for future awareness and actions: "Since then, I have been more concerned about the importance of publishing this data from companies" (418). These comments suggest the activity not only informed students of WikiRate but also that students were able to engage in its purpose for promoting and informing the public on sustainability to address social and environmental challenges.

\section{Skills}

Four sub-themes crystallized when analysing the data for evidence of skills through the WikiRate student engagement project. The first sub-theme related to the expansion of research skills, as students reflected on the overall activity and what skills they felt it developed. One student's comment reflects on the pedagogical design, saying "[t]his class teaches you autonomy and precision. We have to search into dozen of pages of CSR reports to find sometimes one data. But it is worth the work" (13). Another student points to their ability to research company performance, "I can reveal where companies are thriving and struggling, and I can direct attention and resources toward improvement" (4). This theme is also closely connected to the knowledge of disclosure practices and to learning skills for researching company information, as this student exclaims, "it is horrible to see how companies can trick naive people into thinking they are sustainable without proper research" (300).

The second skills sub-theme builds on this with an emphasis on,the development of analytical and critical thinking skills. For many students, their critical thinking was developed through questioning or challenging organisational data or practices. Students offered statements such as "I have become more critical of the quality and contribution of companies reporting SDG's, have started to recognise a lot of disclosure and reporting as public relations instead of real impact" (33). They also offered comments around how they will use their critical thinking skills in this context, for example "I have also become aware of the need to not always take things at face value" (29) and "I have learnt that not all companies are as honest as you may 
think"(87). Students also reported on their increased analytical skills and often applied this to their future work, as shown in this student comment "I want to go into research so this has provided a solid foundation and overview of analysing data and working on it" (24).

The third skills sub-theme relates to improved judgement and decision-making skills, and an ability to make more informed choices.

"I feel like it will allow me to make more informed decisions and this will impact my own choices when potentially investing in a company, as I will be able to understand what is meant by company transparency" (118).

"I think now that I have looked deeper into the effect companies' mis-reporting has on the environment and socially, I can make better judgements about companies and question their social and environmental accountability" (195).

This was reinforced by statements on how they wish to make decisions when they are leaders in their own organisations. For example, "As I move into my professional practice, knowledge about the sustainability goals can help me to encourage others to make decisions that will help reach these goals and also increase awareness"(345), and "it will affect my decision-making positively as sustainability is now such a large consideration"(209). Some students described a new holistic or systems thinking approach to thinking about organisational sustainability, with one student claiming: "It will help in the decision-making process, to ensure a comprehensive assessment of different actions and their impacts on people and environment" (457), and another concurring by stating, "It has helped me to expand my... critical thinking processes" (65).

The fourth and final skills sub-theme was 'translation' skills, that is, students' skills and ability to interpret the documents and claims that they scrutinised.. Several students made sense of what they were reading in terms of organisational ethics and trust, for example "It will help me recognise which companies I should trust" (222). Others imagined how they would use the SDGs in their future work "Since I am now more aware of the SDGs, I will use this in the future to ensure the accountability of the business I work for and see how we can improve the practices to meet more of the SDGs" (223).

\section{Attitudes}

A clear majority of students demonstrated a change in attitude towards sustainability after participating in WikiRate research, the exception being a small number of statements along the lines of: "To be frank, my thoughts on SDGs have not much changed because I 
acknowledged the importance of it since before working on this activity" (2). Analysis of positive responses to attitude change were categorised into six sub-themes.

The first shift in attitudes relates to organisational CSR practices, captured in thoughts and ideas about how organisations should behave, report or disclose. For some students this is with optimism, while for others responsible organisational behaviour and the future of corporate reporting on CSR looks bleak. Students offered statements such as "I learned that companies are not actually showing their contribution in fulfilling the SDGs. If they do want to show their contribution, they should adopt a more vibrant reporting culture" (6), and "Companies need to engage more in CSR and report it better" (476). Student comments suggest a positive shift in attitude and recognition of the importance of CSR and the SDGs following analysis of corporate self-reporting on the impact of CSR activities. For example, "I viewed them as idealistic rather than realistic, but after seeing the extent to which companies have actually been willing to adopt and work towards them I am more optimistic for the future" (34). Other students support this optimism: "My thoughts and attitudes have changed as I didn't believe that businesses were trying to improve on sustainable development" (234).

The second shift in attitude suggests the emerging development of a sustainability mindset, characterised by making connections between CSR and the SDGs to the wellbeing of humans, society and the environment. One student states: "I don't think SDGs are remote from us anymore, we are one part of the world" (19). Others echo this sentiment, "I have a much more socially responsible outlook since engaging in this activity, as I understand that businesses have a greater effect on sustainability then I first thought" (35), and "I realize that this kind of topic is related to everyone everywhere and we all have the responsibility to achieve these goals together" (16). Reflecting on the WikiRate experience one student says, "The activity has enlightened me and allowed me to understand and identify problems in the world, and the Goals which have been set in order to minimise these problems" (170). This statement suggests an authentic understanding of the purpose of the SDGs and how they aim to tackle global issues".

A third attitude sub-theme emerged around the challenge of achieving the SDGs and living sustainably. A variety of views were expressed about progress towards the SDGs. "I think we still have a long way to go to achieve a sustainable life, however we are making progress through the implementation of SDGs" (57); another added, "It has made me realise that there 
is still a lot of work that needs to be done in this area in order to achieve the goals by 2030, and has made me think that there need to be stricter measures in order to achieve this" (56). Shifting attitudes are reflected further when students talk about an organisation's relationship with the environment. "It made me realise that firms pollute a lot and many times exploit the nature just for money. It all starts with people, if everyone is aware, the companies won't be able to pollute" (55). Some students acknowledged their own role in working towards a sustainable world: "It has created a deeper awareness of the issues pertinent to society and the duty I have as part of society to encourage corporations to disclose information and act responsibly in their environmental and social activities" (342).

The fourth attitude sub-theme centred on attitudes as consumers. One student captured this sentiment in terms of their own purchasing practices:

"Since engaging in this activity I perceive that my thoughts and attitudes on the SDG's and CSR have been impacted positively. I have noticed myself thinking about the social and environmental impacts associated with, for instance, the production of animal products such as sheep skin seat covers when walking past such retailers and thinking about if and what these companies are reporting/ disclosing and whether they are taking corrective action to achieve social sustainability" (326).

Changes in consumer behaviour are also reflected in statements, such as, "[this activity] made me more aware of the importance of sustainability and may impact on my choice to consume particular brands and products" (20), and "[my attitudes] have changed significantly in order to help achieve these Goals since engaging in the activity. I want to help and will be looking into other businesses in order that they help to" (314).

The fifth attitude sub-theme suggest changes in their own sustainability behaviours, mostly reflected in comments relating to the environment: "It has motivated and inspired me to become more aware of the planet and environment by doing more to help out" (472); and "I have gained more responsibilities in what I do that would affect the environment" (75). Other students spoke of changes in their current workplace attitudes and intentions to act more responsibly. "In my company where I work, for example we print tons of pages every day. We should generally pay more attention to sustainability" (387). "It has motivated and inspired me to become more aware of the planet and environment by doing more to help out" (472).

The sixth and final sub-theme related to attitude change and revealed shifts in thoughts about careers and future behaviours as a professional. "It will make me socially aware of morals 
and values when working for companies in the future" (97). "I will now have something else to look at when applying for jobs" (147). For other students, it was reflected in how they saw themselves as future employees, with statements such as "[I will have] greater awareness and consideration in the future when pursuing my career and making key business decisions" (246). "It has made me more aware of the large amount of impact that businesses have on the environment. It has allowed me to reflect on my own actions as well, and [made me] more aware for the future in the areas that I may work" (231).

\section{Summary of Findings}

This research project aimed to explore student learning through the WikiRate student engagement project in relation to knowledge, skills and attitudes as markers of competences for sustainability and the development of a sustainability mindset. The findings suggest that after engaging with WikiRate, students had extended knowledge and understanding on five dimensions, categorised as knowledge of CSR concepts; knowledge of CSR in context; knowledge of disclosure practices; knowledge of how CSR will inform their own future professional practice (personal employability); and knowledge of WikiRate. Furthermore, students reported the development of four types of skill: research skills; analytical and critical thinking skills; decision-making skills; and 'translation' skills. This development of knowledge and skills was accompanied by one or a number of shifts in attitude, which we categorise as attitudes in respect of: organisational CSR practices, global issues, global responsibilities, attitudes as a consumer, and attitudes towards personal sustainability behaviours. Together, growth in all three KSA domains points towards increasing competencies in sustainability, and progress towards the development of a sustainability mindset, as defined by Rimanoczy (2013).

Findings suggest that the WikiRate student engagement innovation has the capacity not only to teach students about sustainability, but to encourage students to move towards sustainability, something Petersen Boring (2010) claims is not achieved by delivering content, but through pedagogies that cultivate skills, dispositions and values. The validity of the findings is strengthened by the methods of data collection and analysis, which sought to elicit students' perspectives of their own transforming awareness, knowledge, skills and attitudes. While such an approach produced student responses that are authentic, messy, still in formulation, tentative and emergent, it is justified for three main reasons. 
First, generating findings on the basis of student comments and perspectives, rather than against learning outcomes, resonates more closely with the intentions and introspection of a sustainability mindset (Rimanoczy, 2016). Second, the Call for Papers for this Special Issue expressed an interest in papers that include and reflect the voice of students, something that Warwick et al. (2017) state is missing in pedagogical research about innovation in sustainability education. By drawing on student perspectives' the paper helps to fill part of this gap in the literature. Third, the nature of the international collaboration itself generated scale in student-generated data, based on the same survey questions, which increased reliability and validity of the data. Using learning outcomes from seven different courses would have rendered such scale impossible, as these were tailored to the different contexts (subject and level of study) of the team of educators, as outlined in Table 1. Furthermore, the international collaboration has led to formation of a community of practice, which enabled knowledge exchange and multiple outputs of data (see Perkiss et al., 2018; Perkiss et al., 2020). Overall, this multi-country research has enabled academics from different disciplines, in five countries, to evaluate the degree to which this innovation might nurture a 'sustainability mindset' by extending their knowledge, developing skills, and affecting a change in attitude.

\section{Conclusions}

In a higher education sector characterised by a squeeze on resources and staff capacity to drive the transformation in business schools that PRME calls for (Warwick, Wyness \& Conway, 2017) the availability of open-access pedagogical resources and platforms, such as WikiRate, offer educators an efficient and effective way of introducing innovation for responsible management education and sustainability in to the curriculum. The adaptability of the platform lends itself to local adaptation and multi-disciplinary approaches to sustainability teaching, as evidenced by the way it has been used by authors of this paper, on undergraduate and postgraduate modules, and in different subject areas of accounting, CSR, and international business.

This international collaborative research project supports other calls for a more studentcentred pedagogical approach to sustainability teaching and research in business and management schools (Doh \& Tashman, 2012; Wyness, Jones \& Klapper, 2015). The authors recognise that the existence and communication of learning outcomes (LOs) for a specific pedagogical effort improves learning for students (Biggs, 1999), and it is crucial that 
teaching, learning and assessment strategies are set up to test whether LOs are achieved (constructive alignment, ibid.). However, this research suggests that the student's voice offers educators powerful additional insights in to the types of knowledge, skills and attitudes learned about and for sustainability on a given course.

The findings in this paper may therefore be useful for educators in a number of ways. Firstly, to pilot an innovation that allows them to deepen integration of sustainability and/or the SDGs in to their curricula using an experiential learning pedagogy. Secondly to use WikiRate as a means to develop students' sustainability mindsets. Thirdly, this research contributes to the ESD field by offering educators a 'student voice' on the utility of the WikiRate student engagement activity as a way of enhancing mindset transformation and stimulating an increased consciousness of the consequences and implications of choices in terms of being a consumer, job seeker and employee. Educators using other innovations may wish to follow a similar research methodology, using a student perspective, to specify the types of knowledge, skills and attitudes developed.

We also acknowledge, however, that this research has limitations, particularly in relation to the uneven distribution of responses to the survey by students. That is, $48 \%$ of all data came from one of the seven modules, a first year module on accounting, which differed markedly from the more mainstream sustainability, responsible management, international business and ethics focus of the other six modules on which WikiRate was piloted. We have yet to ascertain whether this affected the findings. Additionally, while the survey response rate was over $30 \%$ this means that the study did not capture the voices of over 1000 students surveyed, suggesting the need to find new ways to engage students in being more reflective about their own learning.

As discussed earlier, parallel research being carried out by this team of researchers is investigating coordinators' perspectives on the design, implementation and outcomes of the WikiRate student engagement activity. In terms of further research, it would also be useful to examine the design, utility and impact of this project through a longitudinal study that combines educator perceptions, based on learning outcomes, and student perceptions on development of knowledge, skills and attitudes.

While this study is based on the use of WikiRate by seven researchers in five countries, other institutions using WikiRate have expressed an interest in researching the impact of this 
innovation since the study began. This opens up the prospect of expanding the scope of the research to include new institutions and new research questions, as well as using these findings to recruit new adopters. Finally, as WikiRate is one of a number of global pedagogical innovations attracting adopters from around the world, these innovations represent a rich area to explore for researchers of responsible management education.

\section{Conflict of interest}

The authors) declared no potential conflicts of interest with respect to the research, authorship, and/or publication of this article.

\section{Funding}

Part of this research was funded by the University of Wollongong International Linkage Scheme. 


\section{References}

Aguinis, H., \& Glavas, A (2012). What we know and don't know about corporate social Responsibility: a review and research agenda. Journal of Management 38(4), 932-968

Albareda, L., Alcaraz, J.M., Csuri, M., Escudero, M., \& Weybrecht, G.. UNPRME Inspirational Guide for the Implementation of PRME (2012). Greenleaf Publishing, $1^{\text {st }}$ Edition.

Annan-Diab, F., \& Molinari, C., (2017). Interdisciplinarity: Practical approach to advancing education for sustainability and for the Sustainable Development Goals, The International Journal of Management Education, Special Issue: Principles for Responsible Management Education (PRME), 15 (2) Part B, 73-83.

Baartman, L.K.J., Bastiaens, T.J., Kirschner, P.A., \& Van der Vleuten, C.P.N., (2007). Evaluating assessment quality in competence-based education: A qualitative comparison of two frameworks, Educational Research Review, Vol. 2, 114-129.

Bell, R., (2015). Developing the Next Generation of Entrepreneurs: Giving Students the Opportunity to Gain Experience and Thrive, The International Journal of Management Education (2015), Vol. 13, No. 1, pp. 37-47. http://doi.org/10.1016/j.ijme.2014.12.002

Biggs, J. (1999), Teaching for Quality Learning at University, Society for Research into Higher Education \& Open University Press, Maidenhead.

Brammer, S.J., \& Pavelin, S. (2006). Corporate reputation and social performance: the importance of fit. Journal of Management Studies, 43(3), 435-455.

Chopra, P.K., \& Kanji, G.K. (2010). Emotional intelligence: A catalyst for inspirational leadership and management excellence. Total Quality Management, 21 (10) 971-1004.

Christmann, P., Taylor, G (2006). Firm self-regulation through international certifiable standards: determinants of symbolic versus substantive implementation. Journal of International Business Studies 37(6), 863-878.

Doh, J., \& Tashman, P., (2012). Half a world away: The integration and assimilation of corporate social responsibility, sustainability, and sustainable development in business school curricula. Corporate Social Responsibility and Environmental Management, 21, 131-142.

Elkington, J. (2018). 25 Years Ago I Coined the Phrase "Triple Bottom Line”. Here's Why It's Time to Rethink It. Harvard Business Review, Digital Article, June $25^{\text {th }}$.

Fairfield, K.D. (2018). Educating for a Sustainability Mindset, Journal of Management for Global Sustainability Volume 6, Issue 1, 2018: 21-44.

Figuero, P.S., \& Raufflet, E., (2015). Sustainability in higher education: A systematic review with focus on management education. Journal of Cleaner Production, 106, 22-33.

Forray, J.M., \& Leigh, J.S.A. (2012). A Primer on the Principles for Responsible Management Education: Intellectual roots and waves of change. Journal of Management Education, 36 (3), 295-309. 
Forray, J.M., Leigh, J.S.A., \& Goodnight, J.E., (2016). Teaching methods and the Kolb learning cycle: Pedagogical approaches in the Principles for Responsible Management Education domain. In R.Sunley \& J. Leigh (eds), Educating for Responsible Management: Putting Theory into Practice, Greenleaf Publishing/PRME Book Series - For Responsibility in Management Education.

Glaser, B. G. \& Strauss, A. L. (1967). The Discovery of Grounded Theory. Strategies for Qualitative Research. Chicago: Aldine.

Haertle, J., Parkes, C., Murray, A., \& Hayes, R., (2017). PRME: Building a global movement on responsible management education, The International Journal of Management Education, Special Issue: Principles for Responsible Management Education (PRME), 15 (2) Part B, 6672.

Hesselbarth, C. \& Schaltegger, S., 2014. Educating change agents for sustainability: Learnings from the first sustainability management master of business administration. Journal of Cleaner Production, Volume 62, 24-36.

Kopnina, H., (2017). Teaching Sustainable Development Goals in the Netherlands; A critical approach, Environmental Education Research, 24 (9), 1268-1283.

DOI: $10.1080 / 13504622.2017 .1303819$.

Krathwohl, D.R., Bloom, B.S., \& Masia, B.B. (1964). Taxonomy of educational objectives, the classification of educational goals, Handbook II: Affective domain. New York: David McKay Co., Inc.

Lacy, P., Cooper, T., Hayward, R., \& Neuberger, L. (2010). A New Era of Sustainability: UN Global Compact-Accenture CEO Study. Retrieved December 10th 2018 from https://www.unglobalcompact.org/docs/news_events/8.1/UNGC_Accenture_CEO_Study_20 10.pdf.

Laasch, O., \& Moosmayer, D.C. (2015). Responsible Management Competences: An Integrative Portfolio for Sustainability, Responsibility, and Ethics. CRME Working Paper 22015.

Lozano, R. et al., 2011. Declarations for sustainability in higher education: Becoming better leaders, through addressing the university system. Journal of Cleaner Production, Volume $48,10-19$.

Mahoney, L.S., Thorne, L., Cecil, L., \& LaGore, W. (2013). A research note on standalone corporate social responsibility reports: Signaling or greenwashing? Critical Perspectives on Accounting, 24 (4-5), 350-359.

Mills, R., DePaoli, S., Diplaris, S., Gkatziaki, V., Papadopoulos, S., Prasad, S.R., McCutcheon, E., Kapadia, V., \& Hirche, P. (2016). WikiRate.org - Leveraging Collective Awareness to Understand Companies' Environmental, Social and Governance Performance, In: Bagnoli F. et al. (Eds.) Internet Science. INSCI 2016. Lecture Notes in Computer Science, Vol 9934. Springer, Cham. DOI https://doi.org/10.1007/978-3-319-45982-0_7 
Molthan-Hill, P. (Ed) (2017). The Business Student's Guide to Sustainable Management: Principles and Practice, Greenleaf Publishing/PRME Book Series - For Responsibility in Management Education.

Murray, A., Baden, D., Cashian, P., Wersun, A., \& Haynes, K. (Eds.) (2014). UNPRME Inspirational Guide for the Implementation of PRME, UK and Ireland Edition. Greenleaf Publishing.

Nguyen, N.C., Graham, D., Ross, H., Maani, K., \& Bosch, O. (2012). Educating systems thinking for sustainability: Experience with a developing country. Systems Research and Behavioural Science, 29(1), 14-29.

OECD: Organisation for Economic Cooperation and Development (2018). The Future of Education and Skills, Education 2030: The Future We Want. Available at https:/www.oecd.org/education/2030/E2030\%20Position\%20Paper\%20(05.04.2018).pdf . Last accessed December $31^{\text {st }} 2018$.

Ortiz, D., \& Huber-Heim, K., (2017). From information to empowerment: teaching sustainable business development by enabling an experiential and participatory problemsolving process in the classroom, The International Journal of Management Education, Special Issue: Principles for Responsible Management Education (PRME), 15 (2) Part B, 318-331.

Parkes, C., Buono, A.F., \& Howaidy, G., (Eds.) (2017). Special Issue: Principles for Responsible Management Education (PRME), The International Journal of Management Education, Available online at www.sciencedirect.com .

Perkiss, S., Dean, B.A., Gibbons, B., Heithaus, T., Wersun, A., Gonzalez-Perez, M.A., Anastasiadis, S., Acosta, P., Mesick, R., Jun, H. \& Mills, R. (2018). WikiRate Student Engagement Report: International Case Studies. University of Wollongong, WikiRate \& PRME: Wollongong, Australia. ISBN: 978-1-74128-302-0.

Perkiss, S., Dean, B. A., Gibbons, Gonzalez-Perez, M. A., B., Heithaus, T., Acosta, P., Mills, R., Anastasiadis, S., Bayerlein, L., Wersun, A., Mesick, R., \& Jun, H., (2020).

"Learning experientially for corporate social responsibility: International applications of the WikiRate project”. In Taras, V., M. A. Gonzalez-Perez, and K. Lynden (eds), The Palgrave Handbook of Learning and Teaching International Business and Management (in press). UK: Palgrave Macmillan..

Petersen Boring, W., "Western Civilization and Sustainability: Reflections on CrossPollinating the Humanities and Environmental Science." Environmental History 15 (2), 288304.

Rimanoczy, I. (2016). A holistic learning approach for responsible management education, in Sunley, R., and Leigh, J. (Eds.) (2016). In Educating For Responsible Management Education: Putting Theory into practice, Greenleaf Publishing, 159-184.

Sharkey, A.J. \& Bromley, P. (2015), "Can ratings have indirect effects? Evidence from the organizational response to peers environmental ratings", American Sociological Review, Vol. 80 (1), 63-91. 
Sipos, Y., Battisti, B. \& Grimm, K. (2008). Achieving transformative sustainability learning: Engaging head, hands and heart. International Journal of Sustainability in Higher Education, $9(1), 68-86$.

Storey, M., Killian, S., \& O’Regan, P. (2017). Responsible management education: Mapping the field in the context of the SDGs. The International Journal of Management Education, Special Issue: Principles for Responsible Management Education (PRME), 15 (2) Part B, 93104.

Stubbs, W., \& Schapper, J., 2011. Two approaches to curriculum development for educating for sustainability and CSR. International Journal of Sustainability in Higher Education, 12(3), 259-268.

Sunley, R., \& Leigh, J. (Eds.) (2016). Educating For Responsible Management Education: Putting Theory into practice, Greenleaf Publishing.

Warwick, P., Wyness, L., \& Conway, W., (2017). 'Think of the future': Managing change from students' perspectives of an undergraduate sustainable business programme. The International Journal of Management Education, Special Issue: Principles for Responsible Management Education (PRME), 15 (2) Part B, 192-204.

WEC; Net Impact, 2011. Sustainability skills for a changing world: An assessment of what global companies need from business schools. Available at http://www.unprme.org/resourcedocs/wecnetimpactreport2011.pdf Last accessed May 13th 2019.

Wiek, A., Withycombe, L. \& Redman, C., 2011. Key competences in sustainability: A reference framework for academic program development. Sustainability Science, 6 (2), 203218.

Wyness, L., Jones, P., \& Klapper, R., (2015). Sustainability: What the entrepreneurship educators think. Education + Training, 57 (8/9), 834-852. 
Figure 1: Example of Wikirate Project Research Page

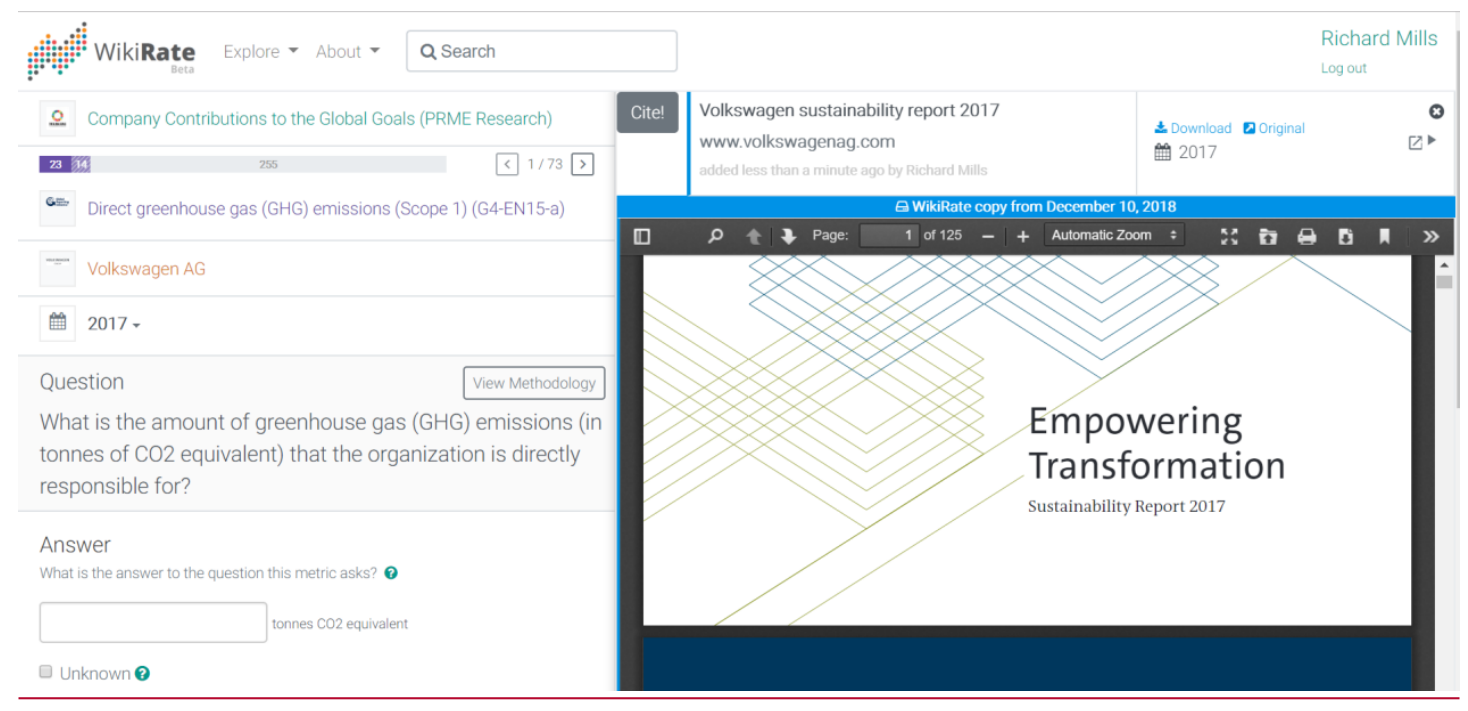


Table 1: WikiRate international collaborative research partners, modules and student numbers

\begin{tabular}{|l|l|l|}
\hline University, Country & Course (module) description, level & No. students \\
\hline $\begin{array}{l}\text { University of Wollongong, } \\
\text { Australia }\end{array}$ & Business capstone, final year, undergraduate & 42 \\
\cline { 2 - 3 } & $\begin{array}{l}\text { Introductory accounting, first year, } \\
\text { undergraduate }\end{array}$ & 760 \\
\hline $\begin{array}{l}\text { Glasgow Caledonian } \\
\text { University, Scotland, UK }\end{array}$ & $\begin{array}{l}\text { Sustainability, corporate responsibility and } \\
\text { ethics, final year, undergraduate }\end{array}$ & 220 \\
\hline Universidad Icesi, Colombia & CSR Course, final year, undergraduate & 27 \\
\hline $\begin{array}{l}\text { University of Applied } \\
\text { Science, Austria }\end{array}$ & $\begin{array}{l}\text { Case studies in business and sustainability, } \\
\text { final year, undergraduate }\end{array}$ & 82 \\
\hline $\begin{array}{l}\text { Universidad EAFIT, } \\
\text { Colombia }\end{array}$ & Ethics and CSR, final year, undergraduate \\
\hline $\begin{array}{l}\text { Royal Holloway, University } \\
\text { of London, UK }\end{array}$ & $\begin{array}{l}\text { Project work for managers - sustainability } \\
\text { and society, postgraduate }\end{array}$ & 300 \\
\hline $\begin{array}{l}\text { EWHA Woman's University, } \\
\text { South Korea }\end{array}$ & Special topics in international business & 130 \\
\hline Total students & & 1,575 \\
\hline
\end{tabular}


Table 2. Coding themes related to knowledge, skills and attitudes (KSA)

\begin{tabular}{|c|c|c|}
\hline Knowledge (knowing) & Skills (doing) & Attitudes (being) \\
\hline $\begin{array}{l}\text { Sub-themes } \\
\text { 1. Knowledge of CSR } \\
\text { concepts } \\
\text { 2. Knowledge of CSR in } \\
\text { context } \\
\text { 3. Knowledge of disclosure } \\
\text { practices } \\
\text { 4. Knowledge of how CSR } \\
\text { will inform their own } \\
\text { future professional } \\
\text { practice } \\
\text { 5. Knowledge of WikiRate }\end{array}$ & $\begin{array}{l}\text { Sub-themes } \\
\text { 1. Research skills } \\
\text { 2. Analytical and critical } \\
\text { thinking skills } \\
\text { 3. Judgement or decision } \\
\text { making skills } \\
\text { 4. Translation skills }\end{array}$ & $\begin{array}{l}\text { Sub-themes } \\
\text { 1. Attitudes towards } \\
\text { organisational CSR } \\
\text { practices } \\
\text { 2. Attitudes towards global } \\
\text { issues } \\
\text { 3. Attitudes towards global } \\
\text { responsibilities } \\
\text { 4. Attitudes as a consumer } \\
\text { 5. Attitudes towards personal } \\
\text { sustainability behaviours } \\
\text { 6. Attitudes of professional- } \\
\text { self }\end{array}$ \\
\hline
\end{tabular}

